\title{
Lucebert $^{1}$ en de religie: Een oratorium
}

\begin{abstract}
This article reviews the intertextual relations between the poetry of the Dutch poet Lucebert and the Bible. Although Lucebert is by no means a religious poet he freely uses Biblical citations and allusions in his poetry. This has special relevance for one of his newest volumes of poetry entitled Troost de hysterische robot - Gedichten en een oratorium (Console the hysterical robot - Poems and an oratorio). The last part of this title refers to an oratorio - which can be defined as a lyrical-musical drama which usually has a religious substance. The Biblical jargon that Lucebert uses does not only refer to texts but also refers to isolated words or phrases which belong to Biblical or religious jargon in general. In his reflections on human destiny and fate, the poet uses many anchoring texts from the Bible. One comes to the conclusion that Lucebert's poems do not fall within the framework of a religious system, but he does use religion and then especially Biblical allusions to testify to his dissatisfaction with established institutions which include the church. The main stylistic device he uses to reach his objective is antithesis, which is also a topic of discussion in this article.
\end{abstract}

\section{Ter inleiding}

In dit artikel wordt het een en ander onderzocht ten aanzien van Luceberts omgang met de Bijbel. Vervolgens worden conclusies getrokken over de religieuze ingesteldheid van Lucebert - dit vooral naar aanleiding van Troost de hysterische robot gedichten en een oratorium (1989). De middelen die hij gebruikt - met name de antitese - om deze religieuze ingesteldheid tot uiting te brengen, worden ook onder het zoeklicht geplaatst.

Troost de hysterische robot is de derde dichtbundel van Lucebert na zijn ontwaken uit een literaire winterslaap van bijna 16 jaar, waaraan met de verschijning van Oogsten in de dwaaltuin van 1981 een einde kwam.

I Luccbert is op 10 mei 1994 overleden 
Sedert Mooi uitzicht \& andere kurioziteiten van 1965 was er namelijk niets oorspronkelijks meer in bundelvorm verschenen. Er waren nog wel wat losse gedichten, gelegenheidsverzen, gedichten die in 1974 in Verzamelde gedichten werden opgenomen en daarna leek het of de dichterlijke stem verstild was. Lucebert had, zo werd aangenomen, finaal voor de beeldende kunst gekozen.

Oogsten in de dwaaltuin werd in 1982 gevolgd door De moerasruiter uit het paradijs met de nu al bekende toevoeging van een grammofoonplaat met gedichten, die Lucebert zelf voorleest en waarmee de dichter het principe bevestigt dat poëzie eigenlijk gehoord moet worden. Aad Nuis (1983:1) verwees na de verschijning van deze twee bundels naar "een feestgedruis rond de wederopstanding van de dichter Lucebert".

Met Troost de hysterische robot staat Lucebert weer in vol dichterlijk onaat op het literaire toneel. Zijn dichterschap is inmiddels verder versterkt met de verschijning van Van de roerloze woelgeest (1993).

\section{Een wezenstrek in Luceberts werk}

In een verscheidenheid van recensies en andere besprekingen wordt melding gemaakt van het feit dat de trant van Lucebert's dichterschap in een tweede fase thematisch en wat taal betreft steeds wentelt om het spel van de tegenstellingen. Dat heeft te maken met, wat al dikwijls genoemd is, Luceberts "taalacrobatiek". Nijmeijer (1983:1) verwijst naar de tegenstelling "die in veel van Lucebert's vroegere poëzie garant stond voor een taalspel vol risico's". Hij is bij uitnemendheid een taalanarchist die het, zo lijkt het althans, bij een eerste oogopslag niet zo nauw neemt met de regels van de grammatica van het Nederlands.

In De Tijd (26 juni 1981) maakt Ad Zuiderent de opmerking dat Lucebert's poëzie niet zonder deze tegenstellingen kan bestaan. Zuiderent typeert het gedicht, en dan het ideale gedicht, als een gegeven van duisterheid en helderheid "... bevestiging en protest ... evenwicht en ontsporing ... vlees én vis. Een vat vol tegenstrijdigheden dus, en een uitnodiging tot tegenspraak".

Deze obsessie ten aanzien van de tegenstellingen bestaat reeds vanaf het begin van zijn dichterschap - de titels van zijn vroege bundels, van de eersten tot de laatsten, geven er al een aanduiding van:

- de analphabetische naam met de tegenstelling van naamgeving en benoeming en het analfabetisme.

- van de afgrond en de luchtmens met de afgrond tegenover het hemelruim.

- val voor vliegengod met de val tegenover vliegend/zwevend bewegen. 
- De moerasruiter uit het paradijs waarin moeras en paradijs weer onverzoenbaar schijnen.

- In de titel, Van de roerloze woelgeest, wordt beweging en roerloosheid tegenover elkaar gesteld.

Als titel zit Troost de hysterische robot-Gedichten en een oratorium vol tegenstellingen met aan de ene kant het woord robot in de betekenis á la Van Dale (1993:2563) van een "kunstmens, mechanisme dat min of meer de gedaante van een mens heeft en bewegingen, verrichtingen of arbeid kan uitvoeren; ...". Hiertegenover staan hoedanigheden, die menselijk zijn: troost en hysterie. In het tweede deel van de titel wordt verwezen naar een oratorium met de betekenis van een "ten dele episch, ten dele lyrisch muzikaal drama zonder toneelschikking, van ernstige, meestal bijbelse inhoud voor zang en orkest of orgel". Neem daarbij nog andere betekenissen van oratorium als "niet openbaar bedehuis; bidvertrek, voorzien van crucifix, klein altaar enz." (Van Dale, 1993:2152), dan wordt de tegenstelling tussen oratorium en robot maximaal gespannen.

Eigenlijk zijn de meeste gedichten van Lucebert die hier aan de orde komen ook constellaties van tegenstellingen. In aansluiting hierbij wijst Cornets de Groot (1967:144) op een algemeen procédé in het dichterlijk bedrijf van Lucebert, dat volgens hem, te vergelijken valt met een heiligverklaringsproces met zijn twee advocaten: de advocaat van God en de advocaat van de duivel. Lucebert kiest, aldus Cornets de Groot, de rol van de duivel. Hij verzet zich tegen de canonisering - bijvoorbeeld van de poëzie. Het paradoxale is natuurlijk dat hij uiteindelijk toch poëzie produceert die "... des te heller komt te stralen" (Cornets de Groot, 1967:144).

Het construeren van antitesen door afwijkend taalgebruik, gebruikmaking van neologismen, het surrealistische bijeenbringen van uiteenlopende zaken eist van de lezer een creatieve betrokkenheid bij het interpreteren van Luceberts gedichten - vooral de gedichten van het oratorium. Er wordt een bijzonder beroep op de lezer gedaan met betrekking tot het associëren, het leggen van verbanden en het invullen van hiaten.

\section{De stofomslag}

Net als in het geval van De moerasruiter uit het paradiss verzorgde Lucebert zelf de stofomslag van Troost de hysterische robot. Met de betekenis in gedachte van robot als een kunstmens bevat de tekening alle associaties daarmee: een hoofd met vier ogen en vier antennes, verder twee ronde voeten met onderscheidenlijk links en rechts vier en vijf antennes. Het vervormide geheel, een gebochelde figuur, is verder gemonteerd met banden en schroeven of klinknagels. Het mense- 
lijkste aan de robot is zijn mond (opengerekt in een grijnslag of een noodkreet), vier ogen, vier neusgaten en een uitgestrekte ann.

De kleuren die aangebracht zijn hebben waarschijnlijk betekenis. Geel is de kleur van de uitstraling rondom de robotfiguur met associaties met zon en licht, wat weer op zijn beurt een aanduiding geeft van onder andere intellect, wijsheid, geestelijke rijpheid (De Vries, 1974:513). Met een grijze omlijning van de tekening en een inkleuring van grijs van de robot wordt weer een tegengestelde associatie opgeroepen van onder andere droefheid, rouw en boetedoening (De Vries, 1974:228). De tegenstelling van het menselijke en het niet-menselijke wordt dus reeds op het buitenblad aangebracht en verwoordt in de titel, waar in de wisselwerking met het beeld, de hysterie effectief verbeeld wordt in een dubbel stel ogen en vier neusgaten en de opengerekte mond - als mens-robot volkomen overstuur dus. Het beeld lijkt op een machtige poging tot uitreiking die op niets uitloopt - er is namelijk beeldgewijs geen antwoord op de geimpliceerde uitroep of liever noodkreet.

\section{Thematische samenhang}

De tekening op de stofomslag vormt een iconische intertekst met de inhoud van deze bundel en dan in het bijzonder met het tweede deel van de bundel met de titel Oratorium, waarop ik me verder zal toespitsen. De wereldproblematiek van het menselijk bestaan wordt hier aangeroerd. Het gaat over het verlies van medemenselijkheid en een toenemende liefdeloosheid waarin woord en klank aan verschrilling onderworpen zijn:

Verminkte zinnen

Geschonden woorden

Woorden die het zingen

Haast verhinderen

(1989:55)

Er zijn verder verwijzingen naar de menselijke eenzaamheid (p. 55); de macht van het materialisme (p. 57); recht en gerechtigheid (p. 60); gewetenloosheid en gewelddadigheid (p. 61); woordbreuk en lamlendigheid (p. 62); zelfzucht (p. 63); liefdeloosheid (p. 65); wraak en wraakzucht (p. 67), grootheidswaan en dekadentie (p. 69); koersloosheid ("... laat ons weer sporen/Op het pad dat we zijn verloren", p. 70); fatalisme en uitzichtloosheid ("Elk systeem baart zijn ruine", p. 77) en ontgoocheling ten aanzien van de kunst (p. 78).

Alles wordt samengevat in de vertwijfeling van de gekwelde geesten: "en ook de kiesschijf van de liefde is kapot" (1989:65). De actanten in dit dichtwerk hebben soms raakpunten met het klassieke oratorium zoals we dat kennen in bijvoorbeeld de Mattheus-Passie van Händel: een koor, solozang, een geest ontdaan, het kind 
van zijn tijd, het gerecht, de rechtvaardige, de zieke stem, de heks, de tovenaar, de gekwelde geesten, de ironikus, de boetvaardige zondaar, de boeteling, de sarkastikus, de tovenaar, de heks, de technikus, de robot, een eenzame vrouw, een eenzame man en de eenzamen.

Waar de uiterlijke vorm van een oratorium wel aanwezig is - er zijn vier koren en drie solo's - biedt de inhoud een tegenstelling met de meestal Bijbels-evangelische inslag ervan. Lucebert's oratorium houdt zich thematisch bezig met seculaire zaken zoals hierboven vermeld: Van Domselaar (1989) verwijst naar een dosis cultuurpessimisme. Oosterman (1989) meent dat het oratorium “ ... een allegorie van deze tijd is. Het is te lezen als kritiek op de toenemende rol van de technologie, van de door technocraten bestuurde wereld waarin de mens wordt gereduceerd tot een robot".

\section{Het Bijbels jargon}

Tegenstrijdig met Luceberts, intratekstueel gezien, negatieve houding tegenover godsdienst en religie is zijn gebruik van een Bijbels jargon in zijn oeuvre en dan in het bijzonder in de onderhavige tekst.

Lucebert heeft zich nooit positief opgesteld tegenover kerk en godsdienst hoewel hij klaarblijkelijk de Bijbel goed kent. In "de openbaringen doden de kerk" (1974: 219) noemt hij de kerk:

\footnotetext{
... kapstok van krankzinnigen ...

"uw hoge ogen om al het gemijmer van verwarde wolken dichten niet het schietgat in de biechtstoel

niet de hardlijvige zender in de bijbel

en de zondag blijft stijf staan voor de meinacht ...'
}

In "het vlees is woord geworden" (1974:20) met een woordspeling op de bekende woorden van Johannes 1:14 "Het woord is vlees geworden ..." gebruikt de dichter een Bijbels gegeven voor een mededeling over zijn poëtica

Op dergelijke wijze wordt ook in het oratorium van een Bijbels jargon gebruik gemaakt, allerminst om iets mee te delen over het evangelie. Het Bijbels evangelie loopt voor de Christen uit op de verlossing door het lijden van Christus, terwijl Lucebert's oratorium een dieptepunt bereikt in "het lied van de robot" (1989:74) waarin de ontmenselijking tot de uiterste consequenties naar voren komt, tot zelfs in de deformatie van de taal, tot een mechanische robottaal waarin alle adjectieven, die meestal de vervoermiddelen voor gevoelswaarden zijn, ontbreken. Het resultaat is een lied waarin het nihilisme zegeviert - het menselijke en het dierlijke, zelfs het goddelijke wordt dooreengehaald en analoog aan elkaar gesteld, ook beklemtoond door gedeformeerde syntactische analogieën. 
Goedegebuure (1989) verwijst naar Luceberts "brabbelidioom" en elders (1983) heeft hij het over "woordkramerij" en "verbale geweld":
Hond hij blaffen
Man hij blaffen
Vrouw zij blaffen
Grragh grragh grragh
Moeder zij straffen
Vader hij straffen
God hij straffen

Eindelijk leidt alles tot het nihilistisch slot:

Geen zin

Geen zijn

De traditionele martelaar van het Christendom wordt finaal gedegradeerd in de monoloog van "de andere boeteling" (1989:68):

Niet de martelaar brengt lafenis

Hij is maar bottelaar van kattepis

Let hier terloops op de tegenstelling van de eindrijmwoorden lafenis en kattepis. "Lafenis" roept de associatie op van verkwikking met 'n verfrissende drank. "Kattepis" roept het tegenovergestelde op. In figuurlijke betekenis heeft lafenis te maken met de bevrijding van de pijnen in het vagevuur: de lafenis der ziel (Van Dale, 1984:1513).

Het Bijbels jargon dat Lucebert gebruikt, verwijst in de eerste plaats naar geisoleerde Bijbelse woorden of frasen, bijvoorbeeld:

"verkoren" (55), verbandhoudende met uitverkiezing: eindtijd (55), "In den beginne ..." (62), "verzaligend" (63); "boetvaardige" (66); "loven (67); "een nieuw lichaam" (70); "het verlossend lied" (73); "voorhang" (79).

Er zijn daarnaast ook enkele grotere gehelen van Bijbelse verwijzingen waar het dichterlijke $i k$ steeds met de Bijbel in gesprek treedt door allusies op Bijbelteksten. Dit gesprek loopt steeds uit op een tegenspraak met het Bijbels gegeven. Ik noem een paar voorbeelden:

* Oh had ik toch van alle liefde

Alleen de prille liefde

(1989: 55) 
Hier is een duidelijke verwijzing naar de bekende passage uit de Eerste brief aan de Corinthiërs over de volmaakte liefde. De grondtekst in de Bijbel, die analogisch herhaald wordt luidt:

\author{
maar had de liefde niet, \\ ik ware schallend koper \\ (1 Cor. 13:1) \\ maar had de liefde niet, \\ ik ware niets. \\ (1 Cor. 13:2)
}

De conclusie van de dichter-spreker is dat hij tevreden zal zijn met de prille liefde. Dit staat in tegenstelling tot de conclusie van het Bijbelgedeelte, waar de prille liefde juist afgelegd wordt:

Toen ik een kind was, sprak ik als een kind, voelde ik als een kind, overlegde ik als een kind.

$\mathrm{Nu}$ ik een man ben geworden heb ik afgelegd wat kinderlijk was.

Want nu zien wij nog door een spiegel, in raadselen ...

(1 Cor. 13:11, 12).

* Volkeren verstrooid

Steden gebrandschat

(1989:57)

Deze woorden, uitgesproken door een ontdane geest, bevatten ook weer een verwijzing naar een Bijbels gegeven, namelijk de diaspora van de volkeren. Meer als 150 keer wordt er in de Bijbel melding gemaakt van de verstrooiing der volkeren. Het bekendste Bijbelse voorbeeld, analoog aan Luceberts betoog over de ontaarding van mens en leven, is het verhaal van het Joodse volk dat na de kruisiging van Christus in de diaspora leeft.

In de voorspelling van de verloochening door de apostel Petrus in Marcus 14:27 staat: "Ik zal de herder slaan en de schapen zullen verstrooid worden."

... Plechtstatig knoeit en prakt een ieder mee

Terwijl men wel weet de tafel waaraan gegeten

Was al eeuwen en eeuwen leeg

(1989:60)

Lucebert heeft het hier waarschijnlijk onder andere over het bankroet van de traditionele religie. De paradox van iedereen die meeprakt aan de tafel (een gemeenschapssymbool) en toch aan een lege tafel zit, heeft iets te maken met een Avondmaalstafel die nietszeggend geworden is. Het (geestelijk) voedsel van de volkeren is al eeuwen en eeuwen op. De gemeenzaamheid van de mens, opge- 
sloten in de symboliek van de tafel (Dante heef het over mensa d'amor) is opgeheven.

* Levend brood tot drek verpapt

Op een kartonnen bord in de regen

(1989: 65)

Ook dit citaat met de antitese van levend brood tegenover verpapte drek heeft een onmiskenbare associatie met Bijbels gegeven. Levend brood is in een Bijbelse zin een metafoor voor Christus. Wanneer Christus het wonder van de spijziging van de vijfduizend doet, zegt hij: "Ik ben het brood des levens; wie tot Mij komt, zal nimmermeer hongeren ..." (Joh. 6:35). In deze verzen is de spreker ervan overtuigd dat deze boodschap zijn geldigheid verloren heeft. Hij laat in het gedicht het tegengestelde van de spijziging plaatsvinden.

$\mathrm{Na}$ het koor der gekwelde geesten

Zingt eenzaam de boetvaardige zondaar

Zijn zegeningen zijn kwellingen

Ontloken aan benauwende lusten

Gebukt onder zijn litanie

Plukt hij zijn karige vruchten

Haaruitval podagra en bigotterie (1989:66).

Hier ("de ironikus") wordt vooruitgegrepen op het volgende gedicht: "de monoloog van de boetvaardige zondaar". Van Dale plaatst de betekenis van boetvaardig in de religieuze sfeer: boetvaardig "als boete doende wegens bedreven kwaad door verootmoediging voor God" (Van Dale, 1993:419). Van Dale verwijst ook naar de deugd van de boetvaardigheid, het Sacrament van boetvaardigheid en de stoel van boetvaardigheid, de biechtstoel.

De vruchten van de religieuze boetvaardigheid zijn karig: er blijft niets over dan haaruitval, jicht en vrome kwezelachtigheid.

\section{Lucebert en de religie}

Uit het bovenstaande lijkt het bijna of Lucebert met de Bijbel naast zich gedicht moet hebben. Daarmee is nog geen conclusie getrokken over zijn religieuze ingesteldheid. Het is geen volledig agnosticisme dat zich hier openbaardt. Integendeel, en om dit toe te lichten moet ik teruggaan naar 1951, de Aafjes-affaire. Twee jaar na het verschijnen van Alonaal (Vinkenoog) publiceerde Aafjes in drie artikelen over de experimentele poëzie en had daarin geen goed over voor Lucebert. Oegema (1991:293) somt de kritiek van Aafjes zo op:

Bij de experimentelen bespeurde hij een regressie die angstaanjagend mocht heten, en dat gold dan vooral voor Lucebert ... De atavistische psychologie 
die zich in diens werk uitsprak, herinnerde Aafjes zelfs aan de SS. 'Lees ik Luceberts poëzie, dan heb ik het gevoel dat de SS de poèzie is binnengemarcheerd. Een totalitair stelsel van rauwe gevoelens en instincten, met de laarzen aan van cen verschrikkelijke uniformiteit, uit zich in een duangmatig Sieg Heil van woorden als: oe, a, oer, ei, urinoir'

Het antwoord van Lucebert, wel geladen met ironie, aan Aafjes enkele maanden later in De Groene Amsterdammer van 4 juli 1953 is veelzeggend en mijns inziens steeds van toepassing op het werk van Lucebert. Er wordt beweerd dat Lucebert met deze brief daadwerkelijk een poging heeft ondernomen om een begin van inziclit in zịjn poëzie in mogelijk te maken

Ik haal aan:

$U$ (bedoeld is Aafjes) (houdt het) met het gezond verstand en hoont mij omdat ik animaal stamel, omdat ik in mijn nood en benauwenis het ons dienende dier opzocht. Maar waagt $U$ ook te honen hem die als een lam ter slachting werd geleid en die genoemd wordt het lam Gods? Waarom zou L dat niet durven? De hoogmoed van Uw gezond verstand is wel zo groot, dat Uw geweten, Uw hart, in deze vesting voor het weekworden behoed kan worden, als het plengoffer eens over $U$ wordt uitgestort. Want naarstig verhardt $U$ Uw hart, nu $U$ zijn vijand geworden bent, nu $U$ Uw slapen en verblinding voor het eeuwig leven houdend, alle angst en deemis buitensluit opdat $U$ niet zult horen, opdat $U$ niet in verwarring zult geraken over het feit dat niet alleen het lichaam, maar OOK de logos aan het kruis is genageld en bloedt en het uitschreeuwt: mijn god, mijn god, waarom hebt gij mij verlaten.

Met deze belijdenis wil ik een ogenblijkje stilstaan bij een enkel gedicht uit het oeuvre, "het orakel van monte carlo" (1974:112) waarin de dichter zich naar het schijnt positief uitspreekt over de Christus als martelaar en als navolgenswardig voorbeeld.

Het gedicht wordt traditioneel gezien als een afrekening met het romanticisme van met name de Tachtigers met hun hoofdman Willem Kloos. In tegenstelling tot Kloos wijst het dichterlijke ik met een zekere bewondering (?) op een voorbeeld van een anti-traditionalist, namelijk Christus, de Vorst van de Vrede.

die aan de rechterhand des heeren

die had het door:

de Vrede graast de Kudde voor

De interpretatie zou kumnen zijn dat in tegensteiling tot Willem Kloos die 'met gewoon op straat' liep, Christus juist aards kwam leven Iirgocentrisch gezien kan Vrede in dit gedicht niet anders zijn als een metafoor voor Christus. De theoloog, prof. G.Th. Rothuizen heeft "het mirakel van monte carlo" ook als een 
voorbeeld van Christelijke poèzie bestempeld. Luceberts commentaar hierop was wel dat hij niet in God geloofde. "Ik geloof in het leven, niet in de dood Ik heb geen metafysische conceptie van iets dat boven alles staat" (interview met H.O. Visser, 1968). Ik moet hieraan toevoegen dat er in deze paar regels nog wel andere dimenties zitten. Het gaat hier namelijk ook om een verwijzing naar Bernard ter Haar (1806-1880), gevierde theoloog-dichter, verfoeid door de Tachtigers die hier, aldus Comets de Groot (1968:61) in ere hersteld wordt. Willem van der Paardt (1982:58-72) heeft in eell uitvoerige uiteenzetting (posthuum) aandacht gegeven aan de intertextuele relaties tussen een gedicht van Ter Haar en "het orakel van monte carlo" enerzijds cin iu cunnuculdar van Willem Kloos in 1896 anderzijds (1904:15).

Voor de ergocentrische interpretatie van Vrede als metafoor voor Christus is er een eggo te vinden in de beschouwing van J. Oegema (1991:295), die de afleiding maakt dat Lucebert in Christus een archetype ziet:

Lucebert in navolging van Ball en Arp (opteert) voor een christelijk gekleurd dadaisme - een combinatie van diep-religieuse bewogenlieid enerzijds, en grimmige opstandigheid anderzijds. Beide facetten komen samen in de Christus-figuur, die overeenkomstig een nog te weinig bestudeerde tendens in de romantische traditie - waartoe ook het dadaisme behoort, met zijn explosieve burgerhaat - fungeert als dubbel-archetype van martelaat EN wettenbreker.

\section{Ten slotte}

Troost de hysterische robot valt binnen het patroon van Luceberts dichterschap. In werkelijkheid preekt hij tegen het verval van - om met Vondel te spreken "Dezer werrelt, die zo dwerrelt" ("Kinder-lijck"). Hy bedient zich van het idioom van de Bijbel, maar het gareel, de omraming, is gans anders. Hij spreekt namelijk met religieuze ijver en doet dat als een religieuze dadaïst. En hier sluit ik mij aan bij Oegema's ziening (1991:293-301) onder het opschrift "Religieus dadaïsme". Oegema toont aan dat Lucebert een sterke aansluiting vond by Hugo Ball (overl. 1927), de vader van het Zürichse dadaïsme, die juist in zijn dadaistische periode sterke belangstelling kreeg voor de religie en mystick en ook een genegenheid tot het Rooms-Katholicisme openbaarde. "Hij buigt (hristendom en dada naar elkaar toe ...", aldus Oegema (op. cit., 299).

Dat doet de religieuze Lucebert ten slotte ook in het lied van het laatste kroor met een notie van een mystiek einde:

Ons houdt vogel leven in zijn klauwen

Want wij vliegen als wij vallen

En verrijzen bij het dalen

Naar het geborchte van de bron. 
Het is alleszins duidelijk dat Lucebert geen neiging tot het evangelie heeft. Hij blijft steeds de aartsironicus, de duivelskunstenaar, die zich een naam heeft toegeëigend die boekdelen spreekt: Lucebert (of Lucifer), de duivelskunstenaar of de duivelsadvocaat.

$\mathrm{Hij}$ is en blijft, ongeacht zijn geneigdheid om religieuze en Bijbelse idiomatiek in zijn poëzie op te nemen, een zeer aardse dichter. Jaren geleden zei Th. Govaert (1957:426) van Lucebert, en het blijft steeds van toepassing:

En het enige dat overblijft is de aarde en de aardse mens, die moet trachten in de kleine hem gelaten genoegens een mogelijkheid te vinden om in de chaos die hem omringt verder te leven.

\section{Aangehaalde bronnen}

Cornets de Groot, R. 1967. De zevensprong. Amsterdam : De Bezige Bij

Cornets de Groot, R.A. 1968. Labirimteek. Den Haag : Bert Bakker/Daamen

De Vries, A. 1974. Dictionary of Symbols and Imagery. Amsterdam : North Holland Publishing Co.

Goedegebuure, J. 1983. De poëzie van de Apocalyps. Haagse Post, maart 5.

Goedegebuure, J. 1989. Fictie tweepolig. Haagse Post, juni 3.

Govaart, Th. 1957. Februariezon over de poezie der vijftigers. Streven, 10 (1):419-428.

Kloos, W. 1904. Veertien jaar literatuurgeschiedenis. Amsterdam : S.L. van Looy.

Lucebert. 1953. Open brief aan Bertus Aafjes. De Groene Amsterdammer, juli 4.

Lucebert. 1965. Mooi uitzicht \& andere kuriosileiten. Amsterdam : De Bezige Bij.

Lucebert. 1974. Verzamelde gedichten. Amsterdam: De Bezige Bij

Lucebert. 1981. Oogsten in de dwaaltuin. Amsterdam : De Bezige Bij.

Lucebert. 1982. De moerasnuiter wit het paradijs: gedichten 1981-1982. Amsterdam : De Bezige Bij.

Lucebert. 1989. Troost de hysterische robot: gedichten en een oratorium Amsterdam : De Bezige $\mathrm{Bij}$

Lucebert. 1993. Van de roerloze woelgeest. Amsterdam : De Bezige Bij.

Nijmeijer. 1983. Lucebert in gevecht met zijn taal De Volkskrant. 1, maart 11

Oegema, J. 1991. Religieus dadaisme - De schim van Hugo Ball in Luceberts repliek aan Aafjes. Literatuur, 8 (5):293-301, sept./okt.

Oosterman, J. 1989. Luceberts spijt bij zijn verloren idealen. Hervormd Nederland, juli 15

Van Dale. 1993. Groot Woordenboek der Nederlandse taal. Utrecht/Antwerpen: Van Dale Lexicografie.

Van der Paardt, J. 1982. Tachtig tegen vijftig over tachtig. De Revisor, 9 (5):58-72, okt.

Van Domselaar, K. 1989. Nieuwe bundel van Lucebert: lijkenlucht met pret beschreven Utrechts Nietrwsblad, aug. 18.

Zuiderent, A. 1981. Een pessimistische Lucebert. De Tijd, juni 26.

\section{Potchefstroomse Universiteit vir CHO}


